Klinichna khirurhiia. 2018 October;85(10):66-70.

DOI: $10.26779 / 2522-1396.2018 .10 .66$

\title{
Органосохраняющая хирургия рака почки
}

\section{С. П. Степушкин, В. П. Чайковский, Р. В. Соколенко, В. А. Черниловский}

Днепропетровская городская многопрофильная клиническая больница № 4, г. Днепр

\section{Organ-preserving surgery of renal cancer}

\author{
S. P. Styopushkin, V. P. Chaikovskyi, R. V. Sokolenko, V. A. Chernylovskyi \\ Dnepropetrovsk Municipal Multidisciplinary Clinical Hospital № 4, City of Dnepr
}

\section{Реферат}

Цель. Представить собственный опыт в свете общепризнанных тенденций органосохраняющей хирургии рака почки. Материалы и методы. С 2008 по декабрь 2017 г. выполнено 127 резекций почки, из них 32 - лапароскопически, в 111 наблюдениях - по поводу рака почки.

Результаты. При открытой резекции почки в 74\% наблюдений применяли тепловую ишемию продолжительностью от 10 до 27 мин, в среднем 14 мин. Во время лапароскопической резекции почки к тепловой ишемии прибегали в $82 \%$ наблюдений, ее продолжительность составляла от 9 до 39 мин, в среднем 26 мин. Средняя продолжительность операции при лапароскопической резекции почки составляла в среднем $(170 \pm 40)$ мин, при открытом доступе $-(104 \pm 40)$ мин. После обоих типов операций гистологически подтвержден негативный край резекции. За период наблюдения рецидив почечно-клеточного рака (ПКР) выявлен у 3 (2,4\%) больных после открытой резекции почки на стадии ТЗа (гистологически - опухолевые эмболы в сегментарных сосудах). Всем этим пациентам успешно выполнена лапароскопическая нефрэктомия. Безрецидивная выживаемость составила 97,6\%.

Выводы. Выполнение лапароскопической резекции почки безопасно у пациентов с опухолями в стадии рТ1 и не сопряжено с большим количеством периоперационных осложнений в сравнении с открытой резекцией почки, однако при этом достоверно увеличивается продолжительность тепловой ишемии почки. Для тщательно отобранных пациентов среди оперативных доступов предпочтение следует отдавать тем способам, которые могут быть выполнены без тепловой ишемии почки.

ключевые слова: резекция почки; резекция единственной почки; рак почки; тепловая ишемия; декапсуляция почки; органосохраняющая хирургия; лапароскопия; лапароскопическая резекция почки

Abstract

Objective. To present own experience in a light of generally accepted tendencies in organ-preserving surgery of renal cancer. Materials and methods. From 2008 to Dec. 2017 yr there were performed 127 renal resections, of them 32 - laparoscopically, in 111 observations - for renal cancer.

Results. In open renal resection in $74 \%$ of observations the thermal ischemia was applied during $10-27 \mathrm{~min}, 14 \mathrm{~min}$ at average. During laparoscopic renal resection the thermal ischemia was used in $82 \%$ of observations, its duration have constituted $9-39$ $\mathrm{min}, 26 \mathrm{~min}$ at average. Average duration of operation in laparoscopic renal resection have constituted (170 \pm 40$) \mathrm{min}$, while the open access one $-(104 \pm 40) \mathrm{min}$. After both types of operations a histologically negative edge of resection was confirmed. During period of observation a recurrence of a renal-cellular cancer was revealed in $3(2.4 \%)$ patients after open renal resection on Stage T3a (histologically - tumoral emboli in segmental vessels). Laparoscopic nephrectomy was done in all of these patients. A disease-free survival have constituted $97.6 \%$

Conclusion. Performance of laparoscopic renal resection is secure in patients with tumor in Stage pT1 and is not connected with big quantity of perioperative complications, comparing with open renal resection, but in this situation a duration of renal thermal ischemia enhances trustworthily. For strictly selected patients among operative accesses it is mandatory to choose those, which may be conducted without renal thermal ischemia.

Key words: renal resection; resection of a single kidney; renal cancer; thermal ischemia; renal decapsulation; organ-preserving surgery; laparoscopy; laparoscopic renal resection.

Радикальную нефрэктомию долгое время считали «золотым стандартом» хирургического лечения больных с ПКР. Ряд авторов продемонстрировали сравниваемость онкологических результатов после радикальной нефрэктомии и резекции почки у больных с ПКР в стадии Т1а [1 - 5]. В то же время было показано, что у больных после радикальной нефрэктомии явно ухудшается почечная функция [6 - 8]. В 2009 г. А. C. Novick, S. C. Campbell предложили стандартизованный подход к хирургическому лечению локальных опухолей в стадии Т1 (диаметр 7 см и менее). Органосохраняющая хирургия была признана радикальным способом лечения ПКР. Для пациентов с «малыми» опухолями (диаметром 4 см и менее) резекция почки стала приоритетным видом хирургического лечения в срав- нении с радикальной нефрэктомией. Основная цель органосохраняющей хирургии, а следовательно, и основное отличие резекции почки от радикальной нефрэктомии - это максимально возможное сохранение паренхимы почки. Со временем были накоплены данные, доказывающие, что даже небольшая потеря почечной функции может уменьшать продолжительность жизни и увеличивать риск развития сердечно-сосудистых заболеваний [9]. В связи с этим представляется исключительно важным сохранение как можно большего объема почечной паренхимы.

Цель исследования: представить собственный опыт в свете общепризнанных тенденций органосохраняющей хирургии рака почки. 


\section{Материалы и методы исследования}

В урологическом отделении Днепропетровской городской многопрофильной клинической больницы № 4 за период с 2008 по декабрь 2017 г. выполнено 127 резекций почки, из них 32 - лапароскопически, в 111 наблюдениях - по поводу рака почки.

Открытая резекция почки выполнена 95 больным (1я группа). Женщин было 45 (47\%), мужчин - 50 (53\%) в возрасте от 38 до 79 лет, средний возраст составил 57 лет. Поражение правой почки отмечено у 52 (55\%) больных, левой - у 43 (45\%). Опухоль локализовалась в верхнем сегменте у 26 (27\%) больных, среднем - у 31 (33\%), нижнем - у 38 (40\%). Опухоли были диаметром от 1,5 до 7,5 cм, средний диаметр - 3,8 см. По нефрометрической шкале R.E.N.A.L. (радиус, экзофитный/эндофитный рост, близость к собирательной системе или почечному синусу, передняя/задняя поверхность и локализация относительно линий полюсов) опухоли оценены в 9 - 10 баллов. Доброкачественные новообразования наблюдали у 14 (15\%) больных. ПКР в стадии Т1а диагностирован у 51 (54\%) больного, Т1в - у 23 (24\%), Т3а - у 7 (7\%) больных.

Лапароскопическая резекция почки выполнена 32 больным (2-я группа). Женщин было 19 (59\%), мужчин - 13 (41\%) в возрасте от 48 до 75 лет, средний возраст составил 54 года. Поражение правой почки отмечено у 21 (66\%) больного, левой - у 11 (34\%). Опухоль локализовалась в верхнем сегменте у 5 (16\%) больных, среднем - у 6 (19\%), нижнем - у 21 (65\%). Опухоли были диаметром от 1,5 до 5,0 см, средний диаметр - 2,9 см. По шкале R.E.N.A.L. опухоли оценены в 6 - 7 баллов. Доброкачественные новообразования наблюдали у 2 (6\%) больных. ПКР в стадии Т1а был у 24 (75\%) больных, Т1в - у 5 (16\%), Т3а - у 1 (3\%) больного.

Диагностическое обследование больных включало клинический осмотр, лабораторные и инструментальные (ультразвуковое исследование - УЗИ, динамическая нефросцинтиграфия, мультиспиральная компьютерная томография с контрастным усилением - МСКТ) методы исследования. По стадии основного заболевания, степени распространенности опухоли, характеру сопутствующих заболеваний и их осложнений, полу и возрасту обе группы больных сопоставимы. У пациентов 2-й группы средний размер удаленной опухоли был меньше, что связано с тщательным отбором больных в начале освоения лапароскопических методик [10]. У 6 пациентов с размерами опухоли менее 7 см по данным МСКТ установлено распространение опухолевого тромба в сегментарные вены почки. Таким больным была выполнена лапароскопическая радикальная нефрэктомия.

Подготовка пациента к открытому оперативному вмешательству и подготовка пациента к выполнению вмешательства из лапароскопического доступа не отличались.

При открытой резекции почки использовали внебрюшинный доступ в десятом-одиннадцатом межреберье.

Несмотря на то что при резекции небольших опухолей без остановки кровотока в почечных сосудах есть возможность выполнения полноценного хирургического вмешательства и минимизируется вероятность послеоперационных осложнений и снижения почечной функции, достаточно часто возникает необходимость в использовании ишемии почки, пораженной опухолевым процессом. Использование методики ишемии почки не только уменышает интраоперационное кровотечение и улучшает доступ к полостной системе за счет снижения тургора почки, но и улучшает возможность визуализации распространения опухоли и позволяет выполнить качественную резекцию всей опухоли в пределах здоровых тканей, а также облегчает ушивание паренхимы почки в области ложа резецированной опухоли.

Пережатие почечной артерии во время открытой резекции почки применяли в 74\% наблюдений. В 5 наблюдениях зажим Сатинского накладывали порциально на часть паренхимы, где локализировалась опухоль. Резекцию выполняли отступив от визуально определяемого края опухоли на 0,5 см в пределах визуально неизмененных тканей. Если происходило вскрытие собирательной системы почки (72\% наблюдений) или ранение сегментарных сосудов (10\%), их герметически ушивали монофиламентной нитью №3-0 на игле 26 мм.

Симультантную нефропиелолитотомию выполнили у 1 больного с сопутствующей мочекаменной болезнью. Интраоперационное стентирование мочеточника применяли только при сочетанной нефропиелолитотомии. Если опухоль локализовалась в среднем сегменте в области ворот почки, выполняли резекцию почки с иссечением губы до почечных сосудов.

Для обеспечения наиболее надежного гемостаза ложе резекции тампонировали гемостатической сеткой Surgicel, на почечную паренхиму накладывали швы монофиламентной нитью № 0 с целью максимального сближения краев раны и укрытия дефекта, образовавшегося после резекции. Последний этап операции - один из важнейших, ведь недостаточная герметизация дефектов приводит к неконтролируемому кровотечению. Особые трудности в ушивании паренхимы почки возникали, если происходили декапсуляция почки или прорезывание капсулы почки при затягивании швов, особенно во время повторной операции на почке, когда отмечали перипроцес на уровне фиброзной капсулы почки.

Декапсуляция иногда возникает на этапе выделения почки и во время резекции опухоли, особенно без применения тепловой ишемии почки, когда четкость визуализации структур ухудшает большое кровотечение. Изза отсутствия капсулы в местах наложения паренхиматозных швов после резекции опухоли почки невозможно создать удовлетворительную компрессию и герметичность в раневом участке почки, что не гарантирует надежный гемостаз и может привести к выполнению вынужденной радикальной нефрэктомии.

Если во время выделения опухоли или самой резекции происходила декапсуляция почки, то на этапе наложения паренхиматозных швов мы использовали метод обертывания почки гемостатической сеткой Surgicel. Швы на паренхиму накладывали сквозь натянутую гемостатическую сетку (Пат. UA №114424). Это позволяло предотвратить прорезывание швами декапсулированной паренхимы почки, достичь достаточного сближения краев раны и создать дополнительный гемостатический эффект. 
У 9,5\% пациентов 1-й группы наблюдали интрапаренхиматозные опухоли. Невозможность выполнить интраоперационно УЗИ побудила нас найти другой способ интраоперационного определения границ расположения интрапаренхиматозных опухолей почки с целью последующей резекции (Пат. UA №109967). Предложенный способ заключается в следующем. Больному перед операцией выполняют МСКТ почек с внутривенным усилением. Частота сканирования срезов должна быть как можно меныше - 0,5 - 1 мм. Изучая данные МСКТ, определяют топографию интрапаренхиматозной опухоли почки по отношению к верхнему и нижнему сегментам, воротам (от передней или задней губы, в зависимости от расположения) почки и внешней поверхности паренхимы (передней и задней) и фиксируют.

Во время выполнения операции после выделения почки из жировой капсулы с помощью стерильной линейки отмечают расстояние от верхнего и нижнего сегментов и ворот почки до краев ожидаемой опухоли согласно топографии, полученной с помощью МСКТ. Выполняют резекцию опухоли с захватом здоровой паренхимы почки в пределах 5 мм.

После исключительной отработки техники и этапов операции открытой резекции почки мы перешли к ее выполнению лапароскопическим методом. К этому времени нами был уже накоплен достаточный опыт лапароскопических вмешательств на верхних мочевыводящих путях.

Лапароскопическую резекцию почки выполняли трансабдоминальным доступом, что включало в себя создание рабочей полости (пневмоперитонеум), установку троакаров и создание операционной зоны. После ревизии брюшной полости мобилизировали восходящую (при резекции правой почки) или нисходящую (при резекции левой почки) ободочную кишку путем рассечения париетальной брюшины в латеральном канале вдоль линии Тольда. С правой стороны на незначительном протяжении мобилизировали толстую и двенадцатиперстную кишки для обнажения передней поверхности нижней полой вены и почечной вены $[11,12]$. Зону резекции почки очищали от жировой клетчатки при помощи биполярного зажима или ультразвукового скальпеля. Тщательно обрабатывали сосуды почечной ножки. Границу резекции отмечали так же, как и при открытой операции, отступив от визуально определяемого края опухоли на 0,5 cм.

Ключом к успешному выполнению лапароскопической резекции почки является адекватный почечный гемостаз для иссечения опухоли и реконструкции собирательной системы в жестко ограниченном временном промежутке. Для достижения адекватного гемостаза в начале освоения методики лапароскопической резекции почки мы раздельно пережимали сосуды почечной ножки при помощи турникетов или металлических клипс типа «Бульдог». Но в последующем стали использовать прямой зажим Сатинского, что обеспечивает более надежное пережатие сосудов почечной ножки, а на снятие ее компрессии требуется значительно меньше времени, тем самым уменьшается продолжительность тепловой ишемии $[10,13]$. Резекцию опухоли, как и при открытом доступе, выполняли в пределах визуально неизмененных тканей при помощи «холодных» ножниц. При вскрытии собирательной системы почки (35\% наблюдений) ее герметично ушивали непрерывным швом самофиксирующейся нитью V-Loc № 3-0. Паренхиму почки ушивали непрерывно монофиламентной нитью №0 на игле 48 мм после предварительной укладки болстера из гемостатической сетки Surgicel в ложе резецированной опухоли. Для сокращения продолжительности этапа ушивания паренхимы и тем самым уменьшения продолжительности тепловой ишемии вместо формирования узлов концы нитей клипировали клипсами HemoLock при создании компрессии паренхимы $[11,12]$. Когда лапароскопическую резекцию почки выполняли без тепловой ишемии, перед этапом резекции опухоли на паренхиму накладывали компрессионные провизорные швы монофиламентной нитью №0 или 1. Это давало возможность в некоторой степени уменьшить интенсивность кровотечения в условиях нулевой ишемии. По окончании операции макропрепарат опухоли удаляли в резиновом контейнере через удлиненную до 3 см рану в месте введения троакара в подвздошной области. Зону резекции дренировали силиконовым дренажом Блейка диаметром 6 мм через рану одного из троакаров на $2-3$ сут.

У 3 пациентов с анатомически единственной почкой резекцию почки выполнили по абсолютным показаниям. Приводим наблюдения.

Пациент В., 48 лет, госпитализирован в отделение с диагнозом: опухоли обеих почек. Первым этапом больному выполнена нефрэктомия слева в связи с опухолевым поражением более 70\% паренхимы почки (гистологически: папиллярный тип ПКР). Через 2 мес больной поступил в отделение для второго этапа лечения. По данным МСКТ: множественные образования правой почки (в верхнем сегменте рядом расположенные образования размерами $34 \times 38$ мм и $17 \times 35$ мм; в среднем $-8 \times 10$ мм, $5 \times 10$ мм; в нижнем $8 \times 9$ мм); состояние после нефрэктомии слева.

Пациенту выполнена открытая резекция пяти опухолей единственной правой почки без тепловой ишемии. Продолжительность операции составила 100 мин, объем интраоперационной кровопотери - 500 мл. Гистологически: образования правой почки - папиллярный ПКР (1 тип) с очагами кровоизлияний, кальциноза, с признаками врастания в капсулу почки, без прорастания в клетчатку.

Пациенту М., 68 лет, ранее в отделении выполнена лапароскопическая радикальная нефрэктомия слева. Гистологически: ПКР, светлоклеточный вариант с прорастанием в капсулу почки, врастанием в околопочечную жировую клетчатку и в стенку крупных сосудов (Т3а). На пятом году регулярного обследования по данным МСКТ у больного выявлена пролонгация заболевания - метастазы в единственную правую почку (очаговые образования в верхнем сегменте размерами 12 × 14 и 6,8 × 7,3 мм, в нижнем переднем - $14 \times 15$ мм).

Пациенту выполнена открытая энуклеорезекция трех опухолей единственной правой почки без тепловой ишемии. Продолжительность операции составила 90 мин, объем интраоперационной кровопотери - 300 мл. 


\begin{tabular}{|c|c|c|c|}
\hline \multicolumn{4}{|c|}{ Сравнительная характеристика открытой и лапароскопической резекции почки } \\
\hline \multirow{2}{*}{ Параметр } & \multicolumn{2}{|c|}{ Резекция } & \multirow{2}{*}{$\mathrm{p}$} \\
\hline & открытая & лапароскопическая & \\
\hline Средняя продолжительность операции, мин & $104(85-150)$ & $170(150-220)$ & $<0,05$ \\
\hline Средний объем кровопотери, мл & $235(100-500)$ & $150(50-400)$ & $<0,05$ \\
\hline Количество койко-дней, сут & $9,5 \pm 6,5$ & $5,5 \pm 1,5$ & $<0,05$ \\
\hline Начало энтерального питания после операции & Через 364 & Через 18 ч & $<0,05$ \\
\hline Длительность применения аналгетиков, ч & $48-56$ & $24-36$ & $<0,05$ \\
\hline
\end{tabular}

Гистологически: образования правой почки - ПКР, светлоклеточный вариант, 2 - 3 степень злокачественности по Фурману, с инвазивным ростом в капсулу узла.

Пациентке Л., 52 года, за 3 года до поступления в отделение выполнена лапароскопическая радикальная нефрэктомия справа. Гистологически: светлоклеточный рак с врастанием в капсулу опухоли и органа. Тогда же у больной выявлена небольшая опухоль левой почки, за которой амбулаторно проводили динамическое наблюдение в течение 3 лет. По данным контрольной МСКТ: состояние после правосторонней нефрэктомии; объемное образование левой почки в заднем сегменте с нечеткими контурами, неоднородной структуры, размерами $14 \times 15 \times 18$ мм.

Пациентке выполнена открытая резекция опухоли единственной левой почки без тепловой ишемии. Продолжительность операции составила 96 мин, объем интраоперационной кровопотери - 500 мл. Гистологически: образование почки - ПКР, светлоклеточный вариант, 1 степень злокачественности по Фурману. По краям резекции опухолевого роста не выявлено.

\section{Результаты}

У пациентов, которым выполнили малотравматичные лапароскопические операции, длительность пребывания в стационаре, сроки начала энтерального питания, длительность применения аналгетиков сократились в 2 раза по сравнению с открытой операцией (см. таблицу).

Во время открытой резекции почки произошло ранение главных сосудов (IV степень по Clavien - Dindo) у 2 (2,1\%) пациентов. Сосуды ушили, кровотечение остановилось. Гематома в области резекции возникла у 1 (1,1\%) пациента после открытой (І степень по Clavien - Dindo) и у 1 (3,1\%) - после лапароскопической (ІІа степень по Clavien - Dindo) операции. Осложнение после открытой резекции купировали консервативно на фоне антибактериальной терапии. Нагноившуюся гематому после лапароскопической резекции пунктировали и аспирировали под контролем УЗИ. Раневую инфекцию наблюдали у $1(1,1 \%)$ пациента после открытой и у 1 (3,1\%) после лапароскопической резекции почки (І степень по Clavien - Dindo). У 1 (3,1\%) пациентки на 24-е сут после лапароскопической резекции почки возникло кровотечение из оперированной почки в связи с образованием артерио-чашечной фистулы (IVa степень по Clavien - Dindo). Консервативная гемостатическая терапия оказалась безуспешной, больной выполнили нефрэктомию. Частота образования уриномы составила 1,1\% после открытой и 3,1\% после лапароскопической резекции почки. Больным с уриномой выполняли стентирование мочеточника опе- рированной почки. В течение первой недели выделение мочи по раневому дренажу прекратилось. Стент удалили через 2 мес.

Никто из пациентов не умер. После обоих типов операций гистологически подтвержден негативный край резекции. За период наблюдения рецидив ПКР выявлен у 3 (2,4\%) пациентов после открытой резекции почки. У 1 пациента рецидивная опухоль 3 см в диаметре на расстоянии около 3 см от зоны резекции первичной опухоли возникла через 3,5 года после открытой операции. У 1 пациента рецидивная опухоль в зоне предыдущей резекции с опухолевым тромбом в почечной вене возникла через 19 мес после открытой операции. У 1 пациента рецидив наблюдали через 21 мес в зоне предыдущей резекции интрапаренхиматозно. Следует отметить, что у всех пациентов рецидивы возникли после резекции почек по поводу рака в стадии ТЗа (гистологически - опухолевые эмболы в сегментарных сосудах). Всем этим пациентам успешно выполнена лапароскопическая нефрэктомия.

Таким образом, безрецидивная выживаемость в нашем исследовании составила 97,6\%.

У больного В. с папиллярным ПКР, которому выполнили резекцию единственной почки, наблюдали прогрессирование заболевания. У него через 22 мес после резекции выявлены метастазы в плевру, гидроторакс справа. Больному выполнены торакоскопия, плевродез, после чего начато проведение таргетной терапии препаратом сорафениб (800 мг в сутки). Через 17 мес после применения сорафениба у больного отмечено прогрессирование заболевания: увеличение лимфатических узлов забрюшинного пространства, формирование гидроторакса. Больному начата терапия препаратом ниволумаб (400 мг в мес) с положительной динамикой. Длительность таргетной терапии на данный момент составила 19 мес.

У больных с интрапаренхиматозными опухолями рецидива опухоли после резекции не наблюдали.

\section{Выводы}

В хирургическом лечении опухолей почек максимальные усилия должны быть направлены на сохранение почки как органа. Успех данных вмешательств возрастает с накоплением опыта хирургом. Выполнение лапароскопической резекции почки безопасно у пациентов с опухолями до 4 см в диаметре и не сопряжено с большим количеством периоперационных осложнений в сравнении с открытой резекцией почки [14, 15], однако при этом достоверно увеличивается продолжительность тепловой ишемии почки. При условии отбора больных среди оперативных доступов предпочтение следует отдавать то- 
му методу, при котором возможно обойтись без тепловой ишемии почки.

\section{References}

1. Raz O, Mendlovic S, Shilo Y, Leibovici D, Sandbank J, Lindner A, et al Positive surgical margins with renal cell carcinoma have a limited influence on long-term oncological outcomes of nephron sparing surgery. Urology. 2010 Feb;75(2):277-80. doi: 10.1016/j.urology.2009.06.110.

2. Marszalek M, Meixl H, Polajnar M, Rauchenwald M, Jeschke K, Madersbacher S. Laparoscopic and open partial nephrectomy: a matchedpair comparison of 200 patients. Eur Urol. 2009 May;55(5):1171-8. doi: 10.1016/j.eururo.2009.01.042.

3. Peycelon M, Hupertan V, Comperat E, Renard-Penna R, Vaessen C, Conort $\mathrm{P}$, et al. Long-term outcomes after nephron sparing surgery for renal cell carcinoma larger than $4 \mathrm{~cm}$. J Urol. 2009 Jan;181(1):35-41. doi: 10.1016/j.juro.2008.09.025

4. Gill IS, Kavoussi LR, Lane BR, Blute ML, Babineau D, Colombo JR Jr, et al. Comparison of 1,800 laparoscopic and open partial nephrectomies for single renal tumors. J Urol. $2007 \mathrm{Jul} ; 178(1): 41-6$.

5. Delakas D, Karyotis I, Daskalopoulos G, Terhorst B, Lymberopoulos S, Cranidis A. Nephron-sparing surgery for localized renal cell carcinoma with a normal contralateral kidney: a European three-center experience. Urology. 2002 Dec;60(6):998-1002. PMID: 12475657.

6. Thompson RH, Boorjian SA, Lohse CM, Leibovich BC, Kwon ED, Cheville JC, et al. Radical nephrectomy for pTla renal masses may be associated with decreased overall survival compared with partial nephrectomy. J Urol. 2008 Feb;179(2):468-71; discussion 472-3. doi: 10.1016/j.juro.2007.09.077.

7. Kogan MI, Gusev AA, Evseev SV. Ocenka pochechnoj funkcii u bol'nyh pochechno-kletochnym rakom do i posle radikal'noj nefrjektomii. Onkourologija. 2011;(4):20-4. [In Russian]
8. Kogan MI, Gusev AA, Evseev SV. Ocenka pochechnyh funkcij i operativnoe lechenie pochechno-kletochnogo raka. Onkourologija. 2013;(1):1723. [In Russian].

9. Go AS, Chertow GM, Fan D, McCulloch CE, Hsu CY. Chronic kidney disease and the risks of death, cardiovascular events, and hospitalization. N Engl J Med. 2004 Sep 23;351(13):1296-305. doi: 10.1056/NEJMoa041031.

10. Stepushkin SP, Chajkovskij VP, Sokolenko RV, Alifanov ID, Tereshhenko PV, Novikov SP, Sergeev VN. Jevoljucija tehniki rezekcii pochki. Ukraïns'kij zhurnal maloinvazivnoï ta endoskopichnoï hirurgiï. 2014;18(1):23-8. [In Russian].

11. Gettman MT, Blute ML, Chow GK, Neururer R, Bartsch G, Peschel R. Robotic-assisted laparoscopic partial nephrectomy: technique and initial clinical experience with DaVinci robotic system. Urology. 2004 Nov;64(5):914-8. doi: 10.1016/j.urology.2004.06.049.

12. Rassweiler JJ, Abbou C, Janetschek G, Jeschke K. Laparoscopic partial nephrectomy. The European experience. Urol Clin North Am. 2000 Nov;27(4):721-36. PMID: 11098770.

13. Teodorovich OV, Galljamov JeA, Jankovskaja IE, et al. Laparo-i retroperitoneoskopicheskaja rezekcija pochki. Urologija. 2011;(3):43-7. [In Russian].

14. Porpiglia F, Mari A, Bertolo R, Antonelli A, Bianchi G, Fidanza F. Partial nephrectomy in clinical $\mathrm{T} 1 \mathrm{~b}$ renal tumors: multicenter comparative study of open, laparoscopic and robot-assisted approach (the RECORd Project). Urology. 2016 Mar;89:45-51. doi: 10.1016/j.urology.2015.08.049.

15. Zhao PT, Richstone L, Kavoussi LR. Laparoscopic partial nephrectomy. Int J Surg. 2016 Dec;36(Pt C):548-553. doi: 10.1016/j.ijsu.2016.04.028. 